\title{
Publisher Correction: Sarcoidosis
}

Johan Grunewald, Jan C. Grutters, Elizabeth V. Arkema, Lesley Ann Saketkoo, David R. Moller and Joachim Müller-Quernheim

Nature Reviews Disease Primers 5, Article number: 45 (2019) https://doi.org/10.1038/s41572019-0096-x Published online 04 July 2019

In the originally published version of Figure 2, a figure permissions line was omitted in error. The correct figure permission line has now been added to the HTML and PDF versions of the article, stating “Adapted from ref.46, CC-BY-4.0 https://creativecommons.org/licenses/ by/4.0/.”. In addition, a typographical error in reference 46 has been corrected.

https://doi.org/10.1038/s41572-019-0107-y I Published online: 16 July 2019 